\title{
O professor pesquisador nas universidades públicas no contexto da internacionalização do capital: a produtividade do trabalho imaterial superqualificado*
}

\author{
João dos Reis Silva Júnior \\ Universidade Federal de São Carlos, Brasil
}

\begin{abstract}
Resumo
O objetivo deste texto é compreender o processo de mercantilização da universidade estatal pública brasileira e de sua identidade institucional. Busca-se compreender este evento tal qual um processo de racionalização social, com origem no Estado reformado e como parte da herança do século $\mathrm{XX}$, articulado com a internacionalização do capitalismo, que terminou como alvo da naturalização do fundo público pelo capital, resultando em reformas das instituições republicanas brasileiras. A universidade, não sem a contraposição de movimentos sociais, políticos e sindicais e de intelectuais que ainda resistem, está sendo transformada em instituição tutelada pelo capital e pelo Estado, tendo o mercado como mediador. A racionalidade mercantil tornou-se o núcleo da Política quando deveria ser a administração pública voltada para o ser humano, com conseqüências perversas para o governo popular democrático distanciando-se de sua origem, para o pensamento intelectual mais crítico, para a esquerda partidária, para a pesquisa sobre as políticas públicas de educação superior e, sobretudo, para o objeto aqui examinado: as atividades e a formação do professor pesquisador das universidades estatais públicas em geral. Enfim, procura-se mostrar que o processo de racionalização, em sua forma histórica atual, tem como essência também histórica a racionalidade de formação social do capitalismo, e, em razão disso, mostra, indiretamente, as orientações deste evento.
\end{abstract}

\section{Palavras-chave}

Educação Superior; Formação Docente; Alienação no Trabalho Docente; Ontologia no Trabalho Docente 


\author{
Reflito! Sei não estar louco \\ Imerso nesta sociedade doente \\ Confesso! De quando em quando \\ Deliro com um bem para todo ser humano ${ }^{1}$
}

\section{Introdução: construindo uma hipótese}

Em artigo intitulado Riqueza concentrada e trabalho em excesso, Márcio Pochmann (2008), professor da Universidade Estadual de Campinas e presidente do Instituto de Pesquisas Econômicas, discorre sobre as modificações nas formas de produção de valor pelas modificações ocorridas e a ocorrer em face da nova proporção da renda com origem no trabalho material e no trabalho imaterial, bem como suas conseqüências. Segundo o economista, para cada " $\mathrm{R} \$ 1$ de riqueza gerada no mundo a partir do esforço físico do trabalho do homem em 2006, havia $\mathrm{R} \$ 9$ de responsabilidade do trabalho de natureza imaterial" (Pochmann, 2008). Sua afirmação considera "a composição do PIB (Produto Interno Bruto) acrescido do conjunto de ativos financeiros em circulação no planeta, que permite associar o trabalho imaterial às atividades terciárias da estrutura de produção de riqueza" (idem). Para ele, portanto, ainda que se considere esta proporção, a produção do valor encontra-se no setor industrial, num hibridismo com as muitas formas de exploração do trabalho imaterial na acumulação flexível.

O autor acrescenta que em "1950, por exemplo, a cada $\mathrm{R} \$ 10$ de riqueza gerados no mundo, somente $\mathrm{R} \$ 4$ provinham do trabalho imaterial" (idem). Isto é, em um período menor que 30 anos "a riqueza associada ao trabalho imaterial cresceu quase $10 \%$, em média, ao ano, enquanto a do trabalho material aumentou a metade disso" (idem). Disto decorre uma profunda mudança no processo de circulação de mercadorias e realização do valor, com conseqüências para o trabalho imaterial.

"Nesse sentido, o PIB dos países torna-se mais leve e com elevada produtividade, tendo o trabalho imaterial como principal força geradora de riqueza no mundo" (idem). Isto é, contrariamente à época de Marx, o trabalho imaterial torna-se mais factível de tornar-se produtivo, "o que exige, em contrapartida, amplos e constantes investimentos em infra-estrutura, em ciência e em tecnologia aplicada" (idem). O que isto significa dito de forma mais direta? Que a ciência, a tecnologia e as inovações tecnológicas tornam- 
se imprescindíveis no momento atual para a "potencialidade renovada de fantástica ampliação da riqueza a partir da base industrial consolidada pela estrutura produtiva existente" (idem). Isto impõe, para o centro das mudanças que assistimos nos últimos 40 anos no mundo e a partir da década de 1980, no Brasil, que a sociabilidade seja alterada na direção de uma "sociabilidade produtiva". Para isto, de um lado as instituições escolares - que são o lugar privilegiado da educação básica - são chamadas para o lugar central no processo de construção desta sociabilidade; de outro, as universidades são postas no centro do processo de formação de professores e de produção de ciência, tecnologia e inovação tecnológica, modificando profundamente a natureza da instituição universitária, das instituições escolares da educação básica e do trabalho do professor.

Voltemos ao excelente artigo de Pochmann (2008): em 2006, "a cada dois ocupados no mundo, um encontrava-se relacionado ao trabalho material, enquanto em 1950 eram três em cada quatro que trabalhavam". Como havíamos destacado que o fenômeno não se põe apenas para o Hemisfério Sul, Pochmann argumenta que nas "economias capitalistas avançadas, só um a cada três ocupados desenvolve trabalho material".

A demanda intensificada do trabalho imaterial constitui-se numa contradição, dado que pressupõe um real crescimento da economia por meio de investimento de capital produtivo, ainda que amalgamado ao capital financeiro, que se põe na condição de macrogestor da economia mundial e das mudanças que vêm sofrendo a classe trabalhadora e o trabalho material e imaterial.

No entanto, no pólo antitético a este apresentado surge uma demanda reformista posta pela própria substância histórica do capitalismo. No plano da economia, a necessidade de contínuo processo de ensino e aprendizagem, como se pode observar no centro da Declaração mundial sobre educação para todos, aprovada na Conferência de Jontiem, promovida pela Organização da Nações Unidas para a Educação, a Ciência e a Cultura, em 1990. Esta data é significativa, um ano após a derrubada do Muro de Berlim - cujos fragmentos foram e ainda são vendidos como souvenir a turistas - e mostra de forma solar o caráter ideológico daquele evento histórico: a vitória do capitalismo liberal, da democracia e da república burguesa, com a astúcia e comemoração de Francis Fukuyama, o qual publica seu famoso e polêmico livro $O$ fim da história e o último homem, pragmaticamente colocando o 
acadêmico no lugar do político e, ao mesmo tempo, buscando legitimar cientificamente o evento político.

Por que amplio ao nível desta mediação a introdução deste artigo, cujo objeto goza de precisão que se estampa no título? Porque esta visada permite articular o específico do trabalho do professor às modificações do trabalho imaterial em meio à acumulação flexível. O momento de internacionalização do capital, no plano econômico, exige uma nova sociabilidade do ser humano. Lembremos Gramsci (1988) em seu primoroso texto Americanismo e fordismo, ao se referir à passagem para o modelo fordista de organização do trabalho, e inspirado em Trotsky, afirma que somente haverá sucesso nas atividades do trabalhador no novo paradigma produtivo se um novo ser humano pensar, sentir e viver em conformidade com as novas relações sociais que derivariam das novas formas de relações de produção. O que Gramsci nos indica naquela mudança da forma histórica do capitalismo é a necessidade da construção de uma nova sociabilidade para o cidadão europeu, em um continente cuja densidade histórica é infinitamente maior que a que era a dos Estados Unidos.

Isto nos está posto desde há quatro décadas em nível planetário e há três décadas para o Brasil. Em decorrência deste movimento, tornamo-nos o país das reformas na década de 1990, com o objetivo de mudança de nossa sociabilidade para a produção de uma "sociabilidade produtiva", para o que são centrais a esfera educacional, a instituição escolar e a universitária, mas, sobretudo, o trabalho do professor.

Com base em pesquisas de longo prazo sobre emprego e desemprego no capitalismo e com uma visão particular da esfera educacional, Pochmann (op. cit.) toca em pontos importantes para o entendimento das mudanças nesta esfera de formação humana - a Educação - e para as profundas alterações que já se estão realizando no trabalho do professor. Acrescento outros traços às boas análises feitas, para compreendermos as mudanças nas instituições escolares de educação básica e nas instituições universitárias no Brasil.

A compreensão das mudanças da identidade da instituição escolar — lugar da prática da educação básica — da instituição universitária e do trabalho do professor (cujo trabalho é imaterial e superqualificado) deve ocorrer por meio do entendimento de dois grandes eixos, dentre outros: o 
primeiro consiste na reforma do Estado posta em movimento em 1995 e em curso até os dias atuais; o segundo realiza-se nas mudanças na produção e valoração do capital. O primeiro realiza-se por meio das reformas das instituições republicanas, da reorganização da sociedade civil e da mudança da sociabilidade do ser humano neste momento do capitalismo; o segundo tem como principais orientações, de um lado, a reestruturação produtiva, que teve seu início sistematizado no Brasil na primeira metade da década de 1980, e de outro, a transformação radical no trabalho imaterial superqualificado, ambos no contexto da acumulação flexível. Esta última condensa as formas "pretéritas" e atuais de exploração do trabalho, atualizadas por novas e eficientes formas de controle e valorização do capital. Nisto consiste a grande e mais relevante inovação do capitalismo para manter sua produtividade, diminuindo seu custo (o trabalho vivo) e, conseqüentemente, realizando o desemprego e a reorganização do mercado de trabalho material e imaterial e a desorganização das formas de representação da classe trabalhadora.

Os dois eixos por meio dos quais é possível compreender mudanças na identidade da instituição universitária e do trabalho do professor encontram-se na necessidade de mudança da sociabilidade para a manutenção das margens de produtividade do capital. Daí decorre o primeiro eixo, relacionado à necessidade de reformas das instituições republicanas brasileiras; para tanto, a matriz é a reforma do Estado.

O segundo eixo a que aludimos anteriormente articula-se à reforma das instituições republicanas. Esta nova taxonomia institucional legalizada pelo novo ordenamento jurídico colocaria em curso no país um extenso e intenso movimento de reformas com o objetivo de produzir um novo pacto social pragmático e nova sociabilidade, a "sociabilidade produtiva". A ciência, a tecnologia e a inovação tornaram-se meios de produção, mudança que produziu a mercantilização das instituições federais de ensino superior (Ifes) e alterou qualitativamente o trabalho do professor pesquisador, um trabalho imaterial e superqualificado. Em acréscimo, o resultado do trabalho do professor pesquisador colocará em movimento, por meio das reformas da educação básica, a constituição de um novo tipo de professor, que formará novas gerações segundo o pacto social que se pretendia construir. Imbricada nessa mudança, está a emergência dos espaços midiáticos, as células de fabricação e a terceirização e, com ela, a exigência de um processo cognitivo 
do trabalhador cujo trabalho está muito mais próximo do trabalho imaterial, adequado à reestruturação produtiva, tendo como paradigma a acumulação flexível.

Destacam-se, ainda, o aumento da expectativa de vida do trabalhador, a desconcentração de plantas industriais de trabalho, o trabalho domiciliar e as reformas relativas ao trabalho, que diminuem os direitos sociais sobre o trabalho, requerem a necessidade de qualificação continuada pela vida toda e novamente reforçam a produção científica pragmática e o aumento do trabalho imaterial e produtivo. Tudo isto modifica a identidade das Ifes, as relações entre o Estado e as instituições, mas, sobretudo, o trabalho do professor pesquisador, como se pôde observar até agora em nossa pesquisa.

Sobre as transformações no trabalho material ou imaterial no Brasil, ver Antunes (2006). Por meio de pesquisas empíricas na maioria dos setores empresariais, o autor mostra como se verificaram as transformações para a exploração nos dois tipos de trabalho e como a acumulação flexível intensificou e precarizou o trabalho material e imaterial no país. O aumento da possibilidade da exploração do trabalho abstrato na condição de acumulação flexível consiste no "acúmulo dos modos de produção servis pré-capitalistas" (Lazzarato, 1997: 11) e leva ao limite da auto-exploração o trabalhador orientado pela nova sociabilidade produtiva. Esta é a novidade mais profunda da acumulação flexível.

No âmbito objetivo das relações sociais, a mais-valia "se esconde sob a ilusão de uma sociedade de produtores independentes de mercadorias, uma sociedade de vendedores de trabalho materializado. Uma sociedade sem vendedores de força de trabalho, posto que o contrato de compra e venda de força de trabalho está metamorfoseado num contrato de fornecimento de mercadorias"2 (Lazzarato, 1997: 34). Em acréscimo, "A exploração do aspecto intelectual do trabalhador, no capitalismo contemporâneo, é uma afirmação da existência de uma 'subjetividade produtiva', relativamente diferente da 'subjetividade operária'" (idem: 104).

Neste sentido, Coli (2006), em Riqueza e Miséria do trabalho no Brasil, coletânea organizada por Ricardo Antunes, analisa o trabalho imaterial do artista do Coro do Estado de São Paulo demonstrando que:

No atual contexto de flexibilização produtiva, os "processos imateriais de produção" tornam-se, no processo de produção em geral, a expressão máxima 
de como as formas de trabalho "pretéritas" e mercantis submetem-se aos novos modos de controle e valorização do capital (Coli, 2006: 315, grifos nossos).

A autora nos mostra que o processo ideológico torna velado o fetichismo da mercadoria força de trabalho e a negação da intensificação humana. E ainda nos possibilita refletir sobre a condição do professor pesquisador a partir do trabalho imaterial do artista quando afirma que:

No contexto do trabalho imaterial, o contrato trabalhista não estabelece uma relação imediata entre "produtividade" e "improdutividade"; ao contrário, estabelece novos parâmetros para a exploração da força de trabalho vivo, que hoje é redimensionado por novas formas de controle do capital, essencialmente a partir de sua subjetividade criativa e participativa no processo de produção. Em dimensão não inédita, no caso do artista em geral [e do professor em particular], altamente qualificado, isso se aprofunda por meio de elementos como a intensificação do trabalho, a precarização das relações de produção (carreira, prestação de serviço, etc.) no interior das instituições às quais prestam serviços. Em resumo, um trabalho que já dependia da subjetividade produtiva [o do professor] do trabalhador resulta, no atual processo de estratégias de mudanças no trabalho produtivo, em profunda sujeição da subjetividade do artista [professor] aos meios e controles do capital (Coli, 2006: 317).

Talvez resida aí eventual chave de leitura que todos os textos da coletânea citada anteriormente, por formas diferentes, nos indicam: o fenômeno do "queimar-se de dentro para fora", o burnout no caso da educação básica e, contraditoriamente, no caso da educação superior, os professores em condições de se aposentarem e que não o fazem. Alguns, quando recebem a comunicação da aposentadoria compulsória, sofrem e chegam a adoecer; há os que se aposentam e continuam trabalhando como voluntários ou em outras instituições públicas ou privadas.

Enfim, tendo sido instado pela coletânea, especialmente pelo texto de Coli, pus-me a refletir sobre o trabalho do professor no momento histórico atual. Por outro lado, Valdemar Sguissardi e eu finalizamos extensa e intensa pesquisa sobre a mercantilização da universidade estatal pública e a modificação qualitativa no trabalho do professor, o que me empurrou de pronto a novo projeto de pesquisa sobre o sentido do trabalho do professor pesquisador nas universidades estatais públicas. Percebemos a necessidade de ampliação da produção de pesquisas que busquem uma especificidade mais profunda no processo escolar de socialização humana e o lugar do 
trabalhador professor e seu trabalho na instituição escolar. Há pouco sobre isto e somos induzidos a fugir deste campo estruturado de pesquisa que articula, de um lado, trabalho e educação, e de outro, as políticas e reformas educacionais.

A universidade estatal pública brasileira passa por um processo de mercantilização de sua identidade institucional. Este processo de racionalização social, com origem no Estado reformado, constitui-se na articulação da herança do século XX (o século da social-democracia e do Estado de bem-estar social) com a internacionalização do capitalismo, e foi alvo da naturalização do fundo público pelo capital, que resultou em reformas das instituições republicanas brasileiras. A universidade, não sem a contraposição de movimentos sociais, como a Associação Nacional de Docentes do Ensino Superior - Sindicato Nacional (Andes-SN), ou de intelectuais que ainda resistem, como os professores Francisco de Oliveira, José Luiz Fiori, Maria Cristina Paoli, Cezar Benjamin, dentre outros, está sendo transformada em instituição tutelada pelo capital e pelo Estado, tendo o mercado como mediador.

A racionalidade mercantil tornou-se o núcleo da Política (que deveria ser a administração pública voltada para o ser humano e não reduzida na direção do crescimento econômico), com conseqüências perversas para o governo popular democrático, que se distancia de sua origem, para o pensamento intelectual mais crítico, para a esquerda partidária, para a pesquisa sobre as políticas públicas de educação superior, mas, sobretudo, para o objeto que aqui interessa examinar, as atividades e a formação do professor pesquisador das universidades estatais públicas em geral. Ainda que se possa aprender, com Theodor Adorno, que em determinados momentos históricos somente é possível resistir por meio da consciência, e não por meio do trabalho e da atividade humana e da política, diante da objetividade histórica, também não é possível contribuir para o adensamento desta mesma objetividade histórica que se vem produzindo ao longo do período de 1995 até a atualidade, sob os governos Fernando Henrique Cardoso (FHC) e Luiz Inácio Lula da Silva. 


\section{O financiamento da instituição universitária pública e a composição do fundo público}

$\mathrm{Na}$ introdução a este pequeno artigo, esboçou-se a construção de uma hipótese e a constituição de alguns elementos mediadores para uma indagação que poderá ser objeto de uma próxima pesquisa; por esta razão, lança-se mão de alguns dados que podem ajudar nessa empresa. Dentre esses elementos, vale destacar o estudo de Pinto (2005), que mostra que, enquanto os Encargos Financeiros da União evoluíram de 4\% do PIB, em 1995, para aproximadamente 10\%, em 2002, com manutenção desta tendência até o ano 2005, a rubrica de Manutenção e Desenvolvimento da Educação oscilou em torno de $1 \%$ do PIB, com leve tendência de queda no mesmo período. Isto permite inferir muito sobre o que se anuncia desde o início deste texto.

Esse ponto de partida fortalece-se ainda mais se paralelamente a isso se observa a composição da receita da União. Ainda segundo Pinto (2005), de 1995 a 2003, as contribuições sociais, como a Contribuição Provisória sobre Movimentação Financeira (CPMF), agora não mais existente, saltaram de um patamar de aproximadamente $9 \%$ para próximo de $15 \%$ do fundo público nesse mesmo período. Sabendo que apenas um percentual dos impostos, parte do fundo público do Estado, é destinado ao financiamento da Educação, fica claro como estão orientadas as políticas de financiamento da educação superior no Brasil, isto é, são parte do processo de naturalização do capital.

As verbas destinadas à Educação ficam cada vez mais escassas e o Estado transfere sua responsabilidade pelo financiamento educacional ao processo de naturalização do fundo público pelo capital, a que acima se fez referência, como herança do século XX. Não é difícil, pois, perceber o outro pólo da contradição em que se vai constituindo a hipótese que aqui se quer construir: as atividades e a formação do professor pesquisador.

No plano político, vigora a racionalidade mercantil no âmbito do Estado (a regulação do mercado), que, no âmbito da educação superior, apresentase como Estado gestor, ao estabelecer instrumentos jurídicos para conformação da identidade universitária, e avaliar, regular e controlar a liberdade acadêmica, essencial às atividades e à formação do professor 
pesquisador das universidades estatais públicas. Isto é suficiente para deslocar o equilíbrio psíquico e psicossomático deste trabalhador, induzindo a grande maioria ao estresse e às doenças psicossomáticas daí decorrentes, como observado nos muitos depoimentos feitos na pesquisa sobre a qual se apóia este texto.

Leia-se um excerto do depoimento de um dos colegas entrevistados para essa pesquisa, no qual ele estabelece relações entre a pós-graduação, a pesquisa, a publicação, o financiamento e as condições objetivas em que isto se faz, segundo o modelo Capes $^{3}$ de avaliação. Neste modelo, além de financiar e induzir a organização dos programas de pós-graduação, esta agência estatal também os avalia, criando um sistema de controle e regulação de cada um deles e do espaço social que eles compõem no Brasil, e induzindo a formação de uma suposta elite de intelectuais gestores que, entre outras decorrências, perpetuam-se em associações e órgãos semelhantes do governo relacionados à pesquisa e à pós-graduação. Tal fato torna cada vez mais constritor o contexto institucional da pós-graduação, o que segundo o depoente, levaria a um alto nível de estresse. Ao comentar a diferença entre a graduação e a pós-graduação, analisa:

Eu digo o seguinte: na pós-graduação o trabalho é muito mais pesado que na graduação (...) Por quê? Na hora que você admite um pós-graduando, você está celebrando com ele praticamente um contrato de que, se não houver sucesso, o fracasso é dos dois. Então, a orientação implica essa responsabilidade (...) O aluno de pós-graduação também é um agoniado e isso ele transmite para o orientador (...) Você está fazendo um contrato de convivência mútua e muita responsabilidade na condução de um processo complexo por cinco anos. A questão do financiamento: você realmente trabalha apertado (...) você é pressionado pelas agências, pressionado pelo aluno, e pressionado por você mesmo, porque cada aluno em geral é sua responsabilidade.

Cabe observar, neste ponto do depoimento, a forma como o modelo de avaliação da Capes, já mencionado, modifica qualitativamente o trabalho do professor que se mostra sujeito aos seus meios e controles ao concordar que "é sua responsabilidade". Outro ponto relevante refere-se à natureza exógena da avaliação imposta à organização do programa avaliado, o qual terá ou não financiamento diante do resultado desta avaliação. Por outro lado, as notas atribuídas aos programas instituem uma concorrência pelos recursos financeiros, instaurando verdadeira competição entre os pesquisadores de 
uma mesma área e acirrando a pressão sobre eles, seus orientandos no doutorado, no mestrado e na iniciação científica (afetando aí os alunos da graduação que pretendem seguir a carreira acadêmica eventualmente) e sobre a própria coordenação, além de propiciarem uma verdadeira "caça às bruxas" internamente aos programas. Novamente aqui o depoente mostra a pseudoformação do professor pesquisador, do graduando de iniciação científica, do mestrando ou doutorando, envoltos no ardil em que se tornou o produtivismo acadêmico induzido pelo Ministério de Ciência e Tecnologia e pelo Ministério da Educação, especialmente na figura da Capes, por financiamentos estatais-mercantis, nas formas de parcerias público-privadas, fundos setoriais, lei de inovação, etc.

Observem-se os jovens que se doutoraram depois da vigência do atual sistema de avaliação da Capes implantado a partir de 1997: hoje parecem muito adaptados ao produtivismo acadêmico, à competitividade. Além de estarem sendo induzidos pela suposta elite de "intelectuais gestores", parecem continuar sua formação de pós-graduando, isto é, o "aluno de pósgraduação também é um agoniado". É perceptível a expansão do número de doutores desta geração com esse perfil, processo que acentua a formação do professor pesquisador "produtor de resultados" de estudos e pesquisas efêmeros - interessa sua posição dentro da área de investigação que é medida de forma quantitativa.

O mesmo colega continua seu relato, acentuando o modelo Capes e avaliando que não seriam as atividades de ensino que os preocupariam, mas a pressão realizada por este modelo.

Nós temos três professores que preferiram sair, e tinha uma colega minha que falou assim: "eu mantenho disciplina". Ela dá duas disciplinas da pósgraduação. "Mas eu quero ser colaboradora porque eu não quero mais orientar." Porque ela não agüenta o estresse e a pressão, parece sofrer muito. Então, eu tenho três professores na pós-graduação que chegaram a esse acordo de manter as disciplinas. "Não tem problema nenhum, vou lá, dou as minhas aulas." Aliás, são excelentes professores de pós-graduação, mas não querem mais orientar.

O prazer da docência na pós-graduação é um fator a ser destacado e, eventualmente, por meio da docência, o sentimento de pertença a um programa de pós-graduação fornece elementos de certo posicionamento acadêmico dentro da área, num contexto de competitividade e concorrência. 
"Mas eu quero ser colaboradora porque eu não quero mais orientar". Por um lado, o não querer orientar sugere não se expor aos perversos mecanismos de regulação e controle da Capes, à competitividade na área, "porque ela não agüenta o estresse e a pressão, parece sofrer muito". Por outro lado, quer esposar-se do que há de positivo no programa de pós-graduação: a docência em seu campo específico de pesquisa, a própria pesquisa (sem financiamento ou com financiamento privado) e publicações sem a "espada de Dâmocles" do Instrumento Anual Coleta Capes, e, sobretudo, ao final do triênio, a avaliação do programa. Trata-se de uma defesa consciente de si em relação aos mecanismos citados.

Mas não se deve creditar toda esta negatividade ao demiurgo "modelo Capes de avaliação"; a cultura dos programas alterou-se e as disputas políticas dentro dos programas de pós-graduação acentuaram-se. A luta dentro da esfera da microfísica do poder, e esta articulada com uma espécie de síndrome do poder pequeno têm realizado destruições de pactos institucionais e de pessoas, levando-as ao divã do psicanalista ou às drogas lícitas e ilícitas. É interessante, a propósito do que se está a analisar, citar o debate sobre $\mathrm{o}$ uso de estimulantes e narcolépicos por pesquisadores e colegas da Universidade de Cambridge segundo a notícia "'Doping' acadêmico vem à tona na universidade" divulgada no Jornal da Ciência da Sociedade Brasileira para o Progresso da Ciência - SBPC (11/03/2008). Neste boletim informativo, pode-se ler:

Num recente comentário na revista Nature, dois pesquisadores da Universidade de Cambridge relataram que cerca de uma dezena de seus colegas admitiram o uso regular de drogas como Adderall, um estimulante, e Provigil, que promove o estado de vigília, para melhorar seu desempenho acadêmico.

Outro depoente, dos muitos colegas que gentilmente se dispuseram a colaborar conosco, correndo o risco de, se identificados, serem estigmatizados na academia (traço cultural dissimulado, mas ainda presente na cultura acadêmica), teve toda sua trajetória profissional na mesma instituição onde até hoje se encontra e mostra a consciência sobre a intensificação e a precarização de seu trabalho, bem como sobre as perversas conseqüências desta reforma na instituição universitária. Depois que expusemos os principais objetivos da investigação, ele relatou: 
Fui credenciado, acredito que em 1997, primeiro para o mestrado e só em 2000 para o doutorado, e agora exerço todas as atividades: graduação, pósgraduação, atividades de pesquisa, atividades administrativas, porque eu faço parte de vários conselhos: conselho do departamento, conselho da pósgraduação aqui da CPG [de sua área de conhecimento], sou vice-presidente da comissão permanente de pessoal docente, e tenho agora sete alunos de pósgraduação e graduação. Então, tudo isso que vocês falaram eu concordo plenamente, a gente só vai acumulando atividades.

Antes de tudo, é necessário demarcar que o ano em que o depoente entrou para a pós-graduação coincide com a implantação do atual modelo Capes de avaliação. Por outro lado, em trabalho desenvolvido para o Instituto Nacional de Estudos e Pesquisas Educacionais Anísio Teixeira (Inep), Sguissardi, Silva Júnior \& Hayashi (2006: 70) observam que:

O ano de 1997, segundo o censo da educação superior no período de 1991 a 2004, é o momento em que há uma inflexão no número de instituições, de cursos, de vagas, mas também, o de uma relativa redução das funções docentes, de funcionários técnicos administrativos, destacadamente no setor público ${ }^{4}$. Um fato na esfera educacional é, sem dúvida, a promulgação da Lei 9.394/96, em dezembro [de 1996], que se tornou um guarda-chuva jurídico à sombra do qual o Poder Executivo pôde fazer a re-configuração da educação superior no Brasil. No entanto, isto somente dar-se-á em razão da presumível vitória de Fernando Henrique Cardoso em 1998 e com isso, a continuidade das mudanças institucionais que se vinha fazendo, marcadamente a partir de 1995, quando se institucionaliza a reforma do Estado brasileiro, e, com isto, garantirse-ia a forma hiperpresidencial, que continuaria até pelo menos o primeiro mandato do governo de Luiz Inácio Lula da Silva.

E acrescentam, de maneira enfática, que:

Em outras palavras, enquanto ao crescimento do total de matrículas na educação superior privada correspondeu um aumento bastante próximo do total de funções docentes, na educação superior pública, o crescimento do total de funções docentes foi inexpressivo ou ínfimo (6\%) para um aumento significativo das matrículas ( $78 \%$, ou 13 vezes maior). Isto implica dizer um real adensamento da carga de trabalho dos docentes da IES, controlado pelos mecanismos da avaliação institucional, com base no Planejamento de Desenvolvimento Institucional e no Projeto Pedagógico. Isto se acentua quando se considera a [...] expansão da pós-graduação havida nos últimos dez anos pós-LDB, posto que os dados sobre os quais trabalhamos são predominantemente relativos à educação superior na esfera da graduação. (Sguissardi; Silva Júnior \& Hayashi, 2006: 73, grifos nossos)

São significativas estas duas conclusões sobre a mudança estrutural da educação superior, pois nos ajudam a compreender a situação dos 
docentes em geral, mas especificamente na esfera estatal pública e na educação superior. Pode-se indicar que, a partir de 1997, o trabalho do professor depoente para nossa pesquisa foi paulatinamente se intensificando no âmbito acadêmico e administrativo. No plano acadêmico, o docente foi credenciado para o mestrado e em seguida para o doutorado, num processo de veloz expansão da pós-graduação no país. Neste período, teve seu trabalho qualitativamente modificado, posto que: 1) a organização do programa de pós-graduação modificou-se em razão da avaliação; 2) a cultura do programa também se modificou, como já apontamos acima. Por outro lado, a própria instituição universitária pública se reestruturou. No plano administrativo, o docente entrevistado afirma que àquela época (2007) exercia todas as atividades: graduação, pós-graduação, atividades de pesquisa, atividades administrativas, e detalhava: "porque eu faço parte de vários conselhos: conselho do departamento, conselho da pós-graduação aqui da CPG [de sua área de conhecimento], sou vice-presidente da comissão permanente de pessoal docente, e tenho agora sete alunos de pós-graduação e graduação". Destaco, aqui, que a formação dos graduandos em iniciação científica, bem como a dos pós-graduandos no mestrado e no doutorado sob responsabilidade do docente, ainda que com a consciência que ele afirma ter das mudanças institucionais, está-se fazendo segundo a racionalidade que se impôs desde a reforma do Estado em 1995 a toda instituição republicana. Tendo consciência do processo, sentindo as mudanças e suas conseqüências, contraditoriamente, o docente quer fazer seu trabalho e continua formando, segundo esta racionalidade, a próxima geração nos três níveis citados. Não é de espantar que encontremos alunos da graduação que necessitam ansiolíticos para irem para a universidade e narcolépticos para dormir. Evento ainda raro, mas que já existe. Volto ao trabalho de Sguissardi, Silva Júnior \& Hayashi (2006: 75), no ponto em que fazem a síntese de sua análise sobre a educação superior do Estado de São Paulo, mas observando que, ainda que com algumas especificidades, esta era a tendência na Região Sudeste e no Brasil. Os autores afirmam que:

Os 14 pontos aqui elencados para realizar a síntese como indicado inicialmente permitem afirmações bem arrazoadas de que houve um largo processo de expansão, ao lado de extenso e intenso processo de mercantilização da educação superior, chegando a ponto de reconfigurar toda esfera deste nível de ensino, especialmente no setor privado, cuja inferência que se pode tirar é a do esgotamento de seus fundamentos organizativos. Quanto à esfera pública, 


\begin{abstract}
existe uma acentuação das funções docentes e, em vez de expansão do número de IES públicas, levantamos a hipótese de aumento de vagas por meio da educação à distância. Em acréscimo, a existência de uma exploração do trabalho docente como resultado de políticas públicas para a educação superior quanto à carreira docente e à avaliação, com graves conseqüências para a própria saúde mental dos trabalhadores na educação superior, incluindo aí, como foi visto, os funcionários técnico-administrativos. Se as razões de tal quadro, no qual não se pode concluir sobre democratização, podem ser creditadas às políticas do governo Lula, mais acentuada deve ser a crítica ao governo FHC. Outrossim, tal qual se busca mostrar no texto, há uma cultura pragmática e profissionalizante [e caritativa] que, originada no início do século $\mathrm{XX}$, se faz presente nos dias atuais e orienta as reformas institucionais em geral e as mudanças na educação superior no período de 1991 a 2004.
\end{abstract}

Estas mudanças observadas por meio dos indicadores financeiros e no cotidiano das universidades, por meio dos depoimentos de nossos colegas, mostram situação de profunda ansiedade e inegável sofrimento do professor pesquisador diante das imposições colocadas sobre sua cabeça, de buscar pesquisas e contatos com pesquisadores de outros países, fazendo do financiamento o grande indutor da intensificação do trabalho deste professor e estimulando o autofinanciamento das universidades - uma lógica muito perversa. Estes são mecanismos do controle do indivíduo, de sua formação humana pelo Estado: um Estado que deveria regular o processo econômico global e, de fato, realiza o inverso: a racionalidade mercantil regula as atividades políticas deste Estado num processo mediado e contraditório.

A Tabela 1 abaixo, da Universidade Federal de Minas Gerais (UFMG), é relevante e exemplifica a situação do quadro docente das Ifes em geral. 
Tabela 1 - Evolução do corpo docente permanente - Titulação - 19952005 - UFMG (2을 semestre, excluídos os docentes de $1^{\circ}$ e $2^{\circ}$ graus e "especialistas")

\begin{tabular}{rccccccc}
\hline Anos & Graduação & $\%$ & Mes trado & $\%$ & Doutorado & $\%$ & Total \\
\hline 1995 & 251 & 12,9 & 857 & 44,1 & 836 & 43 & 1.944 \\
1996 & 222 & 10,9 & 877 & 43,2 & 931 & 45,8 & 2.030 \\
1997 & 201 & 9,3 & 897 & 41,7 & 1.052 & 48,9 & 2.150 \\
1998 & 190 & 8,7 & 861 & 40 & 1.329 & 60,9 & 2.180 \\
1999 & 156 & 7,8 & 732 & 36,7 & 1.106 & 55,4 & 1.994 \\
2000 & 71 & 3,7 & 600 & 31,3 & 1.251 & 65,2 & 1.917 \\
2001 & 155 & 7,2 & 610 & 28,3 & 1.387 & 64,4 & 2.152 \\
2002 & 132 & 6,1 & 615 & 28,4 & 1.414 & 65,4 & 2.161 \\
2003 & 102 & 4,8 & 562 & 26,8 & 1.428 & 68,2 & 2.092 \\
2004 & 414 & 15,9 & 540 & 20,8 & 1.636 & 63,1 & 2.590 \\
2005 & 102 & 4,4 & 600 & 26,1 & 1.592 & 69,3 & 2.294 \\
\hline $\mathbf{1 9 9 5 / 2 0 0 5} \%$ & -59 & -66 & -30 & -41 & 90 & 61 & 18 \\
\hline
\end{tabular}

Fonte: UFMG (2005) 5

Trazemos no espaço deste texto, a título de ilustração de nossa construção da hipótese indicada em epígrafe, a rubrica do financiamento das Ifes. Estes recursos foram a elas destinados no Brasil no período de 1995 (início da reforma do Estado) a 2005, com ênfase para as sete Ifes que formaram a amostra da pesquisa já referida. 
Tabela 2 - Evolução dos recursos totais de todas as Ifes e de sete Ifes da Região Sudeste (amostra da pesquisa) — Todas as fontes - 19952005 - Valores de janeiro de 2006, corrigidos pelo IGP-DI da FGV, em R\$ milhões

\begin{tabular}{cccccccccc|}
\hline Anos & Ufes & UFF & UFJF & UFMG & Unifesp & Unirio & UFU & $\begin{array}{c}\text { Total } \mathbf{7} \\
\text { If es }\end{array}$ & $\begin{array}{c}\text { Total } \\
\text { Ifes }\end{array}$ \\
\hline 1995 & 322 & 767 & 215 & 914 & 485 & 144 & 372 & 3.219 & 16.155 \\
1996 & 281 & 699 & 208 & 839 & 490 & 138 & 341 & 2.996 & 14.558 \\
1997 & 261 & 668 & 206 & 822 & 416 & 141 & 309 & 2.823 & 14.302 \\
1998 & 266 & 655 & 205 & 785 & 384 & 150 & 313 & 2.758 & 14.050 \\
1999 & 254 & 687 & 200 & 779 & 308 & 130 & 325 & 2.683 & 13.753 \\
2000 & 237 & 573 & 200 & 726 & 271 & 115 & 310 & 2.432 & 12.964 \\
2001 & 219 & 522 & 176 & 670 & 255 & 112 & 308 & 2.262 & 11.863 \\
2002 & 221 & 551 & 189 & 673 & 244 & 113 & 291 & 2.282 & 12.063 \\
2003 & 193 & 485 & 166 & 591 & 233 & 101 & 259 & 2.028 & 10.707 \\
2004 & 219 & 507 & 176 & 658 & 311 & 124 & 283 & 2.278 & 11.851 \\
2005 & 216 & 506 & 176 & 649 & 294 & 125 & 276 & 2.242 & 11.465 \\
\hline $\mathbf{1 9 9 5 / 2 0 0 5}$ & $\mathbf{- 3 3 , 0}$ & $\mathbf{- 3 4}$ & $\mathbf{- 1 8}$ & $\mathbf{- 2 9}$ & $\mathbf{- 3 9}$ & $\mathbf{- 1 3}$ & $\mathbf{- 2 6}$ & $\mathbf{- 3 0}$ & $\mathbf{- 2 9}$ \\
\hline$\%$ & & & & & & & & & \\
\hline
\end{tabular}

Fonte: Amaral (2006)

A Tabela 2 mostra a involução do financiamento estatal para cada uma das sete Ifes que constituem a amostra da pesquisa, em comparação com o total dos recursos financeiros destinados a essas sete Ifes da Região Sudeste e ao conjunto de Ifes do país. Ao se observar a característica das séries numéricas representativas do financiamento nos três níveis (a amostra, o universo e o país), vê-se que é nítida a semelhança entre as tendências, o que revela a significativa diminuição dos recursos do Tesouro Nacional alocados para a manutenção do Sistema Federal de Educação Superior. Há uma redução de $30 \%$ (em ordem de grandeza) do financiamento estatal para as instituições da amostra, com exceção da Universidade Federal de Juiz de Fora (UFJF) e da Universidade Federal do Estado do Rio de Janeiro (Unirio), cuja ordem de grandeza da diminuição oscilou em torno de $15 \%$. Não é difícil inferir destes dados a situação que decorre desta redução de financiamento: a necessidade de busca, pelos gestores da Ifes, de formas alternativas de financiamento, entre as quais talvez a primeira consista, de um lado, na mudança e/ou intensificação do trabalho do professor dessas universidades por meio da prestação de serviços, das parcerias público-privadas, dos fundos 
setoriais, da inovação tecnológica; de outro, em programas sociais de caráter compensatório, como o Universidade Aberta, o Programa Universidade para Todos (ProUni), agora associado ao Fundo de Financiamento ao Estudante de Ensino Superior (Fies), o Programa de Expansão e Reestruturação das Universidades Federais (Reuni), inspirado no Processo de Bologna e imposto de forma persuasiva e por pressão financeira somente às Ifes em 2007 e que, dentre outros dispositivos, dobra o número de vagas nas Ifes, a Escola de Gestores, os Programas de Educação a Distância, etc.

É necessário informar que tais inferências se devem também a outros dados e análises, que não se apresentam neste texto, mas fazem parte de outros estudos e pesquisas dos autores Silva Júnior \& Sguissardi (2001), que demonstravam a existência de uma reforma da educação superior "a contagotas" desde 1995, em cujo centro se encontrava, dentre outras tendências, a redução do papel do Estado brasileiro no financiamento das instituições de educação superior, ao lado de um incentivo velado à privatização e internacionalização desse nível educacional.

Outros elementos que podem ilustrar a hipótese em construção referem-se aos gastos com pessoal e encargos sociais de todas as Ifes brasileiras e das sete Ifes da Região Sudeste no período 1995-2005 (com valores a preços de janeiro de 2006, corrigidos pelo IGP-DI da FGV), que mostram a mesma tendência apresentada em relação ao financiamento total (tabela acima). Há uma redução de $29 \%$ nesta rubrica das Ifes no período de 1995 a 2005. Quando é considerada a amostra da pesquisa com as Ifes do Sudeste, a tendência se repete, porém com uma redução em média superior a 30\% (Sguissardi \& Silva Júnior, 2007).

Estes dados revelam a tendência ao fortalecimento da mercantilização e do empresariamento da educação superior no contexto de naturalização do fundo público do Estado pelo capital. Revelam, ainda, que o professor pesquisador, para viver na condição de tempo integral e dedicação exclusiva, vê-se compelido a sujeitar-se às novas faces da educação superior no Brasil. Isto permite inferir que se está vivendo um radical processo de mudança do ser social professor pesquisador. Ele deve, neste contexto, adaptar-se à nova instituição universitária e ao novo pacto social, que se inspira grandemente no pragmatismo que se vem construindo desde os governos de Fernando Henrique Cardoso, com fiel continuidade nos governos de Luiz Inácio Lula da Silva. 
Continuando com exemplos que podem ilustrar o impacto causado no trabalho dos professores e em sua formação humana em geral, mas em particular no dos professores pesquisadores, cito a questão salarial. Segundo a Secretaria de Recursos Humanos do Ministério de Planejamento, Orçamento e Gestão (SRH/MPOG) 6 , o salário do professor titular doutor em regime de dedicação exclusiva reduziu-se de $R \$ 10.092,96$, em 1995, para $R \$$ 7.830,13, em 2007 (em valores corrigidos pelo IGP-DI da FGV, a preços de Janeiro de 2008). Houve, no período em questão, um decréscimo de aproximadamente $25 \%$ dos proventos do professor. Poderíamos inicialmente tomar como pequena a diminuição salarial, pois em nossa cultura os valores inflacionários foram em geral muito altos, especialmente em nossa história recente: quando o presidente Sarney desceu a rampa do Palácio do Planalto pela última vez, a inflação passava de $1.000 \%$ ao ano. Estes altos níveis inflacionários sempre foram o resultado de políticas econômicas que necessitavam da alta inflacionária para compor o fundo público do Estado, sempre sob um impacto profundo de comprometimento da dívida interna no país e de roubo do poder aquisitivo do trabalhador.

No entanto, no período de 1995 a 2007, vivemos uma época em que, também à custa da dívida interna, tivemos uma inflação que oscilou em torno $1,5 \%$, o que implica dizer que $25 \%$ consistem num furto do professor pesquisador das Ifes, tendência que se fez presente também nas universidades estatais públicas em geral.

Considerando as condições mercantis de trabalho, e o que apresentamos sobre o financiamento e as mudanças jurídico-institucionais indicadas - que constituem o horizonte de possibilidades institucionais para a realização do trabalho cotidiano e da formação do professor pesquisador na universidade estatal pública - a tendência de sua formação em geral direciona-se para uma reprodução institucional mercantil e pragmática que nega a liberdade acadêmica, a autonomia universitária e, conseqüentemente, a identidade da instituição universitária, o que consiste numa contradição: por um lado, contribui para a consolidação do pacto social e para o crescimento econômico do país; por outro, exerce a função social de crítica institucional de seu tempo histórico e, sobretudo, de seus próprios objetivos. O processo de mercantilização tende a enfraquecer o equilíbrio histórico liberal desta contradição, fortalecendo o primeiro de seus pólos, enquanto debilita 0 
segundo. Daí dizer-se que a dimensão ontológica do ser social professor pesquisador na direção do humano é, aí, negada.

No entanto, se é negada por mercantilizar o trabalho do professor pesquisador, tornando com isso, em muitos casos, o produto de sua pesquisa em mercadoria (por exemplo, uma patente ou uma metodologia para construção de projetos-políticos pedagógicos para escolas da educação básica), estas quase mercadorias põem em movimento relações sociais por meio do valor de troca, mas somente o fazem tendo como materialidade o valor útil do trabalho mercantilizado. A formação humana do professorpesquisador é contraditória. Por um lado, o valor útil de seu trabalho imaterial e intelectual é historicamente humano e o leva a uma dimensão humana mais intensa. De outro lado, o valor de troca de seu trabalho acadêmico, sendo o guia do processo de sua socialização, traz consigo neste movimento a potência ontológica da formação humana mais intensa. Isso pode ser visto nos itinerários dos depoimentos de nossos colegas.

No início, eles nos pareciam empolgados e orgulhosos de seus trabalhos orientados pelo produtivismo acadêmico; no entanto, quando continuávamos as indagações forçando o pólo sobre o qual, conscientemente ou não, os professores não tocavam, a tomada de consciência parecia se fazer presente. No plano empírico, este movimento fica mais claro. Ainda que tomando consciência da contradição, pretendem continuar seu trabalho, contraditoriamente querem continuar fazendo o trabalho do mesmo jeito, apesar de verem suas famílias desfeitas, de prejudicarem sua saúde por meio do uso de ansiolíticos, anti-depressivos, narcolépticos, sacrificarem seu tempo livre trabalhando nos finais de semana, não saírem um mês completo em férias, não fazerem uso de licenças-prêmio ou sabáticas por entenderem que não teriam o que fazer. Aqui, põe-se a alienação, mas não somente ela: põe-se também, mesmo que de forma não-consciente, a possibilidade de resolução da contradição na direção da formação humana mais intensa. Um dos colegas, quando indagado sobre suas licenças-prêmio, respondeu: "Eu nunca tirei uma licença, nunca! Licença-prêmio, licença sabática, qualquer coisa que você pensar, eu nunca tirei uma licença. (...) Porque o que eu vou fazer em casa durante uma licença-prêmio? O que é que eu vou fazer? Licença sabática (...) Sim, mas viajar pra onde? (...) e grana também, não tenho". Outro colega nos mostra a intensificação do trabalho e o 
desenvolvimento de uma "sociabilidade produtiva" por naturalizarmos em nosso cotidiano os valores que já constituem a cultura institucional mercantilizada e internacionalizada:

Ah sim! Eu acho que depois... Eu já tive por causa do trabalho, do estresse do trabalho eu tive uma gastrite hemorrágica e uma pneumonia junto, e só fiquei afastada 20 dias e foi por estresse, e foi exatamente por essa loucura. E a partir daí a única coisa que eu faço é que eu tiro, pelo menos, meia hora pra sair pra almoçar, isso eu faço! Tiro meia hora, 45 minutos. É aqui próximo, e eu saio pra almoçar, porque antes teve uma época que eu já nem almoçava, entendeu? Eu fazia, comia um lanche aqui e ia direto. Tem muitos professores, eu não sou a exceção, tem vários professores que seguem essa daqui, e tem gente aqui do andar que, por exemplo, chega mais cedo do que eu, porque eu chego $10 \mathrm{~h}$, ou seja, chego tarde. Mas geralmente eu tenho reunião às $9 \mathrm{~h}$, então nesses dias que eu tenho reunião às $9 \mathrm{~h}$ como da CPG, da pós-graduação, eu chego aqui antes das $10 \mathrm{~h}$

O trabalho imaterial de maneira geral tem um limite pouco sensível para o trabalhador e isto é sensível quando se trata de trabalho imaterial superqualificado e que nos dá prazer. Torna-se verdadeira droga lícita e legítima às nossas consciências prenhes dos traços da cultura mercantil e internacionalizada. Frente ao enfraquecimento dos sindicatos e das associações científicas, em nossa defesa não temos discernimento sobre até que ponto nosso trabalho contribui para nossa formação humana e quando avançamos este ponto e nossas atividades voltam-se contra nós. Nossa falta de consciência e a ausência de coletivos a que possamos ter um sentimento de pertença, e que tenham condições de nos defender deste mal invisível, fazem com que nós mesmos nos levemos ao máximo de nossos esforços humanos: o único modo de resistência (resistência que foi verbalizada e negada, mostrando a naturalização da "sociabilidade produtiva") torna-se a doença mental ou somatizada.

O salário, por sua vez, é a mediação do professor pesquisador com o mundo. O salário pode ser a medida do tamanho de sua capacidade de acesso à cultura necessária à sua formação como ser humano e como professor pesquisador, dimensões indissociáveis. Mostra também a potência institucionalmente criada para a adaptação do professor pesquisador às mudanças na universidade reformada, a universidade caritativa e neoprofissional, assim constituída e transformada pelos programas que é impelida a desempenhar, como assinalado anteriormente. O trabalho do 
professor pesquisador e suas atividades mercantilizadas, articuladas com seu salário, serão analisados quando da abordagem de uma eventual chave explicativa sobre o sentido do trabalho do professor na institucionalização mercantil das universidades estatais públicas.

\section{O fundo público e o aumento das instituições}

O aumento das instituições de educação superior públicas no período de 1995 a 2004 é considerável, como se pode observar no gráfico abaixo, o que nos faria supor o aumento de professores em tempo integral para manter o mínimo da produção de pesquisas, publicações tão exigidas pelo Estado e pelo mercado, bem como a formação de profissionais nos cursos de graduação e pós-graduação.

Gráfico 1 . Evolução das taxas de crescimento das IES públicas Brasil e Sudeste - 1995-2004

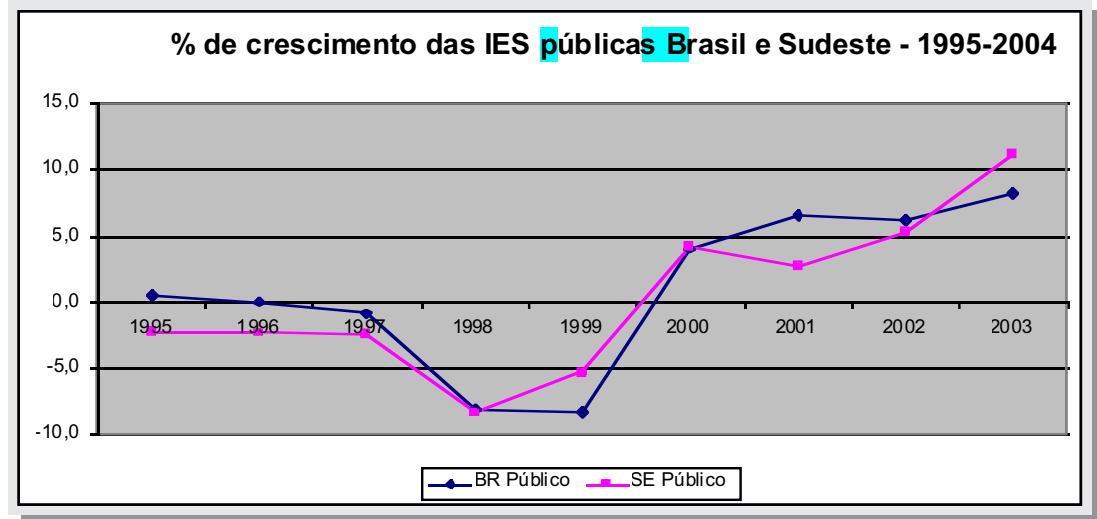

Fonte: INEP (2006: 41)

Por outro lado, quando se observa o gráfico abaixo que mostra, se não a involução, uma ínfima oscilação com tendência à estagnação das vagas dos funcionários técnico-administrativos dos setores público e privado, dá-se o retorno do pessimismo. Se houve um aumento nas instituições em idêntica ordem de grandeza, deveria ter havido o aumento dos técnico-administrativos, posto que as funções da competência desta categoria devem ser realizadas. 
Ainda que no gráfico não estejam discriminados os dois setores, a curva indica a mesma tendência. Uma hipótese imediata é a de que os mesmos funcionários tenham seu trabalho intensificado. Outra hipótese consiste na mudança do perfil deste funcionário, dadas as tecnologias inseridas nas novas formas de gestão das universidades estatais públicas. Os novos sistemas administrativos servidos por espaços tecnológicos midiáticos operam novas relações dos técnico-administrativos com os professores. Muitas funções de competência daquela categoria são repassadas para o professor, com ênfase para o professor pesquisador. Três exemplos, dentre muitos que se poderiam citar: 1) os muitos pareceres emitidos são feitos diretamente, via eletrônica, com agências de fomento ou com revistas, dispensando o trabalho dos funcionários técnico-administrativos; 2) o preenchimento de planilhas de notas de avaliação de alunos on-line; e 3) a apresentação do programa da disciplina on-line, por meio de formulários eletrônicos que "obrigam" o professor a apresentar com rigor seu objetivo e estratégias para o curso que ministrará.

Gráfico 2 - Evolução do número de funcionários técnicoadministrativos — Brasil e Região Sudeste — 1995-2004

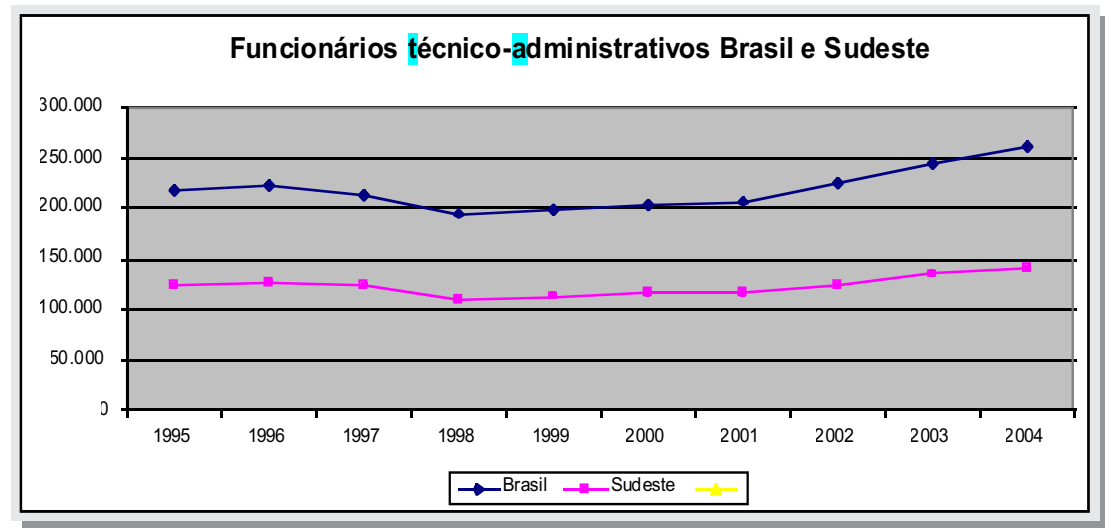

Fonte: INEP (2006: 69)

Para dar um pouco mais de consistência ao que se propôs no início deste texto, ousadamente, já em seu primeiro parágrafo, é importante mostrar 
a evolução dos professores em tempo integral. Tomando como fonte a Diretoria de Estatísticas e Avaliação da Educação Superior do Instituto Nacional de Estudos e Pesquisas Educacionais do Ministério da Educação (MEC-Inep-Deaes), construiu-se o gráfico abaixo, que ilustra bem o que se pretendeu com o título deste texto.

Gráfico 3 - Evolução do número de docentes no período 1995 a 2004 em regime de trabalho de tempo integral - Universidades públicas e privadas - Região Sudeste

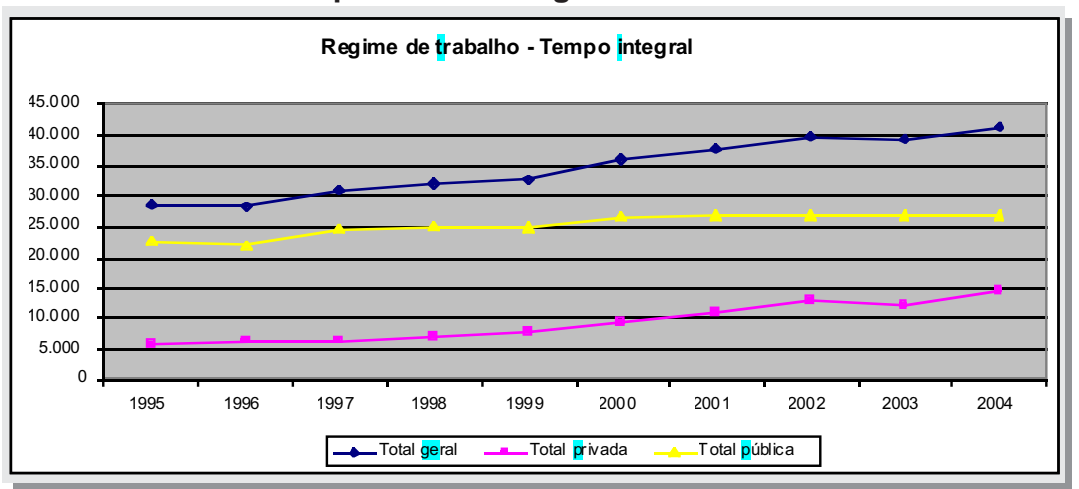

Fonte: INEP (2006)

Apenas um comentário quanto ao mostrado pelo gráfico acima. No período de 1995 a 2004, o número de professores em regime de tempo integral (curva branca), regime em que se encontram todos ou quase todos os professores pesquisadores das universidades estatais públicas, teve um levíssimo aumento: de cerca de 23 mil professores para aproximadamente 26 mil.

No primeiro parágrafo, adiantou-se a hipótese de que as mudanças na identidade institucional da universidade estatal pública se inseriam num processo de racionalização social específico datado e localizado. No entanto, o processo racional a que se aludiu consiste no processo de racionalização social do capitalismo, que é movido a reformas institucionais com origem no Estado. Desta forma, para um entendimento mais consistente do que acontece, não basta a simples apresentação dos dados, mas, em face do 
espaço deste texto, é necessária a produção de visada analítica destes processos de racionalização no capitalismo por meio dos clássicos, que bem apreenderam os tempos longos deste modo de produção. Com isto, poder-seá entender melhor as mudanças de identidade institucional e a formação de novos seres sociais a cada processo de racionalização social exigido pelo capitalismo, sempre com graves conseqüências para o novo ser social.

No século XVIII, Adam Smith (1993), analisando o capitalismo em $A$ riqueza das nações, mostra que o Estado capitalista, para além de representar o capital mediante uma autonomia política relativa, sempre teve um papel econômico, sem o qual o capital jamais se reproduziria plenamente de forma privada, isto é, pela mão invisível do mercado.

Smith (1993) mostra o papel político, mas também o econômico e o belicoso do Estado moderno, antevendo o século da social-democracia e dos presentes diagnósticos e soluções neoliberais, ao mesmo tempo em que oferece a chave para desvendar o período do liberalismo clássico, isto é, a contradição entre a igualdade, a liberdade e a propriedade privada. Segundo Smith (1993), a primeira das despesas do Estado moderno é com a defesa, e em seguida, com a justiça, para a garantia da propriedade privada, o que resulta na desigualdade social entre os homens e no aflorar desta contradição. Isto é, sua teoria econômica somente se sustenta se existir um Estado com tais funções. Aqui se põe o embrião da mercantilização da política no capitalismo. Diante da inevitável desigualdade social desta condição, afirma-se a necessidade inarredável do ordenamento jurídico burguês, dando a forma burocrática à política e à dimensão ideológica do capitalismo.

O terceiro aspecto a que Smith (1993) faz referência é a despesa do Estado para com serviços ou mesmo instituições que possam interessar a uma ou várias unidades de capital: "a criação e a manutenção dos serviços públicos que facilitam o comércio de qualquer país (...) boas estradas, pontes, canais navegáveis, etc., exigirão variadíssimos níveis de despesas nos diferentes períodos da sociedade" (Smith, 1993: 335). A educação é também, para Smith (op. cit.), parte de tais despesas: um serviço público. Trata-se de Estado que, em sua origem, submete a dimensão pública à esfera privada em benefício desta última, no âmbito do próprio Estado republicano. Smith (op. cit.) desvela, no âmbito da economia, o fetiche do Estado liberal e torna clara a contradição entre o público e o privado presente nas relações econômicas 
e sociais. Mostra, assim, a tendência histórica de intensificação da dimensão estatal mercantil que faz com que o Estado dirija suas políticas públicas para o pólo privado da contradição, dada a materialidade da economia. Ao examinar-se esta obra tendo em vista a análise do momento atual, vê-se que existe uma linha de continuidade: as mudanças na forma de Estado estão tendencialmente sempre a serviço do capital.

Em As lutas de classe na França e no 18 Brumário de Luiz Bonaparte (Marx, 1983a, 1983b), dentre outras obras, Marx deixa clara sua concepção de Estado, quando analisa a última fase da revolução: o bonapartismo. Realiza seu intento mostrando a tomada de consciência de classe quando da Constituição Republicana, texto do ordenamento jurídico que torna explícito para os trabalhadores que não se tratava da mudança do regime, mas da transformação do modo de produção. Em seguida, no período da república burguesa, elucida as contradições entre os segmentos da burguesia, que buscavam ter sob seu poder o político e o econômico. Isso possibilitou o golpe de Luís Bonaparte (coup de main) e com ele a produção de uma autonomia relativa do Estado, com destaque para o Poder Executivo. Fez-se aqui esse parênteses para mostrar o embrião das relações entre a economia, a sociedade e o Estado.

Por sua vez, na Itália do início do século $X X$, no momento histórico em que se concretiza a existência de partidos bem organizados, de fortes sindicatos, do sufrágio universal, da grande imprensa e da operária [de que operária?], o pensador Antonio Gramsci, inspirado em Lênin, vislumbra, diferentemente de Marx, diante de uma diferente forma histórica, uma nova esfera: a sociedade civil. Esta é constituída de contradições entre capital e trabalho, entre público e privado e expande a noção de Estado tal qual proposto, com base na filosofia da praxis. Nos Cadernos do Cárcere, Antonio Gramsci (2000) elabora uma concepção ampliada de Estado, na qual este é explicitado como espaço de luta política em razão de conter elementos do Estado restrito, bem como da sociedade civil e de representantes do capital e do trabalho em ambas as esferas.

No entanto, diante da hipótese apresentada e para tratar do tema problematizado neste artigo, é necessário que se procure conhecer a lógica que orientou o processo de racionalização atual e, para isto, como indicado, faz-se necessário conhecer, ainda que de forma analítica, as características 
essenciais do século $X X$, e como esta lógica se atualiza quando do fim da prática do consenso de classes e regulação econômico-social promovidos pelo Estado de bem-estar social.

Voltando a Marx, as modificações das esferas pública e privada mantêm relações entre si, influenciadas, com mediações, pela realização do valor na esfera da circulação de mercadorias. O valor produzido no âmbito da produção é potência, podendo realizar-se ou não na esfera da circulação de mercadorias, o que teria levado Marx (1988) a dizer que a burguesia necessita revolucionar-se sempre para se manter. Há, portanto, uma defasagem entre a produção e a realização do valor. Por outro lado, a demanda do capital é diferente da demanda da classe trabalhadora. $O$ foco daquele são os meios de produção; o desta são os produtos necessários para sua própria reprodução, mediante seu trabalho alienado, a reprodução do capital, bem como a reprodução das contradições da sociedade capitalista. Isto, segundo Marx (1988), provocaria crises cíclicas de superprodução de capital em suas diversas formas (matéria-prima, força de trabalho, produto acabado, capital financeiro, etc.). Isso significa, no médio prazo, queda da produção, dívida interna, inflação e desemprego, além de alta tributação.

A base econômica das teses da social-democracia e do Estado de bem-estar social, de acordo com a Teoria Geral de Keynes, inicia seu declínio na década de 1970. As teses social-democratas transformam-se face o esfacelamento econômico, como se pode observar nos governos Margaret Thatcher na Inglaterra e François Mitterrand na França, sendo que o segundo anuncia em 1982 uma série de medidas em benefício dos trabalhadores, característica das políticas de bem-estar social, mas termina aderindo à privatização, pois não havia mais recursos para o financiamento dessas políticas.

O consenso produzido com base nas teorias keynesianas reproduzia o capital e a força de trabalho por meio do fundo público. Em razão disto, as políticas colocavam o Estado no lugar da classe trabalhadora, na condição de consumidor dos bens da classe operária. Por outro lado, em maior magnitude, colocava o fundo público a serviço do capital. Esta é a chave de leitura para compreendermos o início do processo que tornou o capital industrial produtivo e o capital financeiro uma massa amalgamada sob hegemonia do último. Diante da necessidade de aumento da produtividade em face de crise 
iminente, pesquisas têm seu foco voltado para as inovações sobre o trabalho e ganham grande espaço no âmbito do Estado aquelas voltadas para o trabalho, tendo-se escrito muito sobre este movimento que resultou na reestruturação produtiva. Porém, o que até agora pouco se tem explorado deste nó górdio é o resultado ideológico deixado pelo Estado de bem-estar social.

O pólo antitético da reestruturação produtiva é a naturalização do fundo público por parte do capital, que movimentou todos os seus representantes na direção de reformas do Estado pelo mundo todo, colocando esta instituição reformada a seu serviço, isto é, alterando de forma radical o fundo público na direção de seu benefício. Isto demandou uma reforma de todas as instituições republicanas, especialmente a instituição universitária e a Educação de forma geral, em face da necessidade de alterar todo o processo de racionalização social quando os governos socialdemocratas faliram literalmente e se viram obrigados a aderir aos fundamentos econômicos de Hayek, que atualizam o que Smith já escrevia no século XVIII. A reforma do Estado brasileiro e da educação superior que está em processo desde 1995, cuja perversa forma fenomênica foi acima mostrada, ganha consistência de análise nestes fundamentos. Neles também se encontram elementos para se compreenderem as radicais e profundas mudanças no trabalho do professor pesquisador da universidade estatal pública e suas conseqüências para o ser humano que é, antes de ser o concreto professor.

As políticas públicas passam, no país e no exterior, por um processo de mercantilização ancorado na privatização/mercantilização do espaço público (processo que já se punha de forma embrionária desde os primórdios do capitalismo) e sob o impacto de teorias gerenciais próprias das empresas capitalistas imersas na suposta autonomia ou real heteronomia do mercado, hoje coordenado por organismos multilaterais a agirem em toda extensão do planeta. Quando titular do Ministério da Reforma do Estado e da Administração Federal (Mare), Luiz Carlos Bresser Pereira assim argumentava sobre a necessidade de uma "nova administração pública":

A abordagem gerencial, também conhecida como "nova administração pública", parte do reconhecimento de que os Estados democráticos contemporâneos não são simples instrumentos para garantir a propriedade e os contratos, mas formulam e implementam políticas públicas estratégicas para suas respectivas 
sociedades, tanto na área social quanto na área científica e tecnológica. E para isso é necessário que o Estado utilize práticas gerenciais modernas, sem perder de vista sua função eminentemente pública (Pereira, 1996: 7).

O ex-ministro estabelece aí a matriz teórica, política e ideológica da reforma do Estado e das instituições republicanas, buscando produzir, por meio das políticas públicas e das instituições, um pacto social pragmático. É com base nessa análise da realidade que contextualiza as políticas públicas recentes, em especial das políticas sociais, e é na reflexão exigida pela materialidade histórica, que envolve tanto a contradição público-privado quanto a dimensão central e mercantil do Estado moderno, que se pode compreender melhor a racionalidade político-administrativa dos governos FHC e Lula. Este processo realizou-se nas esferas federal e municipal, no primeiro caso por meio dos governos FHC e, no segundo, pelos governos do Partido dos Trabalhadores (PT). Hoje, apresenta sua horrenda nudez sem mediação alguma, como se pôde observar no âmbito da educação superior: ela se torna naturalizada pelo capital em meio às diferentes formas de fundo público e altera o trabalho imaterial e intelectual, provocando a alienação dos professores, concretizada especialmente por doenças psicossomáticas, dentre outras formas, mesmo que os professores, contraditoriamente, pareçam orgulhar-se de seus trabalhos. Tal fato aparece com freqüência em conversas com colegas e na grande maioria dos depoimentos colhidos durante a pesquisa de campo acima referida, que produziu relevante questão para ser investigada. O que leva a indagar sobre o sentido do trabalho do professor pesquisador das universidades estatais públicas.

* Este artigo tem como referência a pesquisa Mercantilização da Esfera Pública e Universidade - nova Identidade Universitária e Trabalho Docente das IFES da Região Sudente, realizada pelos propessores João do Reis Silva Júnior (UFSCAR) e Valdemar Sguissardi (UNIMEP), com financiamento da FAPESP e do CNPq.

\section{Notas}

1 Fala do personagem de Lima Barreto no filme $A$ volta de Lima Barreto.

2 Este autor e sua contribuição teórica e empírica sobre o trabalho imaterial ganhou visibilidade a partir de 1970. O tema veio à tona na década de 1960 no âmbito do debate da sociologia do trabalho na França, e encontrou eco na Itália no que ficou 
conhecido como neomarxismo e operaísmo. Apesar das simetrias que encontro com Lazzarato e Negri, esta corrente parece manter um diálogo crítico com os autores que tomam a materialidade econômica para análise da reprodução social, tal qual entende György Lukács. A reprodução social tem autonomia relativa dada a materialidade da economia, ainda que esta forma de nos formarmos na condição social - a reprodução social - jamais possa historicamente ser reduzida à economia. Isto nos é claro e disto temos convicção. Mas para tais autores tudo parece indicar que, com o debate sobre a produtividade do trabalho imaterial, a tese marxista sobre a centralidade da categoria trabalho, tornada muito clara por Lukács em sua Ontologia do ser social, é algo criticável, sugerindo certo conservadorismo. Os autores desta corrente parecem compreender o trabalho imaterial embasados no espaço midiático e mediador entre o trabalhador e os meios de produção, o que faria de grande parte da força de trabalho ser imaterial e produtiva. Mas não nos ateremos aqui sobre este debate, que nos exigiria muito mais papel e reflexão. No entanto, em razão das simetrias em relação a Lazzarato e de nossa posição mais próxima de Lukács, aceitamos o argumento do espaço midiático e a exigência de caráter mais imaterial, bem como a própria desconcentração de plantas industriais que contribuiriam para a acentuação da exploração do trabalho, o material produtivo no contexto da acumulação flexível. Mas enfatizamos que a existência destes tipos de trabalho é uma linha de continuidade na economia, que é a esfera fundamental da reprodução social da vida humana e das relações sociais de produção. Em razão disto, procuramos usar a expressão "sociabilidade produtiva" em vez de "subjetividade produtiva", posto que aquela seria construída pela prática social, na qual os valores e alternativas que se movimentam numa atividade humana constroem a subjetividade em cada prática que o ser humano realiza. Portanto, não há uma subjetividade fixa do ser humano, ela é sempre movimento em cada prática social, em cada atividade humana.

3 Capes: Coordenação de Aperfeiçoamento de Pessoal de Nível Superior.

4 Esta análise tem como objeto predominantemente o nível de graduação, não sendo analisada, portanto, de forma direta, a pós-graduação e o impacto que sua expansão teve no período estudado quanto a aumento de cursos, matrículas, vagas, funções docentes, regime de trabalho e funções técnico-administrativas.

5 Disponível em: <http://www.ufmg.br/proplan/relatorios_anuais/relatorio_anual_ 2005/ evolucao_qualificacao_docente.htm>. Acesso em 15 mar. 2008.

6 Disponível em: <http://www.servidor.gov.br>. Acesso em: 29 fev. 2008.

\section{Referências}

AMARAL, Nelson C. (2006). 1995-2005: Execução Orçamentária do Governo Federal. Brasília, DF. [Em linha] [Acedido em: 26 de junho de 2006], Disponível em: $<$ http://www.camara.gov.br>.

ANTUNES, Ricardo (Org.) (2006). Riqueza e Miséria do Trabalho no Brasil. São Paulo: Boitempo. 
COLI, Juliana (2006). A precarização do trabalho imaterial: o caso do cantor do espetáculo lírico. In R. Antunes (Org.), Riqueza e Miséria do Trabalho no Brasil. São Paulo: Boitempo, pp. 98-141.

GRAMSCI, Antonio (1988). Americanismo e fordismo. In A. Gramsci, Maquiavel, a Política e o Estado Moderno. Rio de Janeiro: Civilização Brasileira, pp. 101-178.

GRAMSCI, Antonio (2000). Cadernos do Cárcere. v. 3. Rio de Janeiro: Civilização Brasileira.

INEP (2006). Educação Superior Brasileira: 1991-2004. Brasília: Instituto Nacional de Estudos e Pesquisas Educacionais Anísio Teixeira, (São Paulo) [Em linha] [Acedido em 10 Março. 2008, http://www.publicacoes.inep.gov.br/].

JORNAL DA CIÊNCIA (2008). Brasil: Sociedade Brasileira para o Progresso da Ciência, 11 de março de 2008. [Em linha] [Acedido em 29 Março. 2008, http:www.jornaldaciencia.org.br/ detalhe.jsp?id=54782].

KEYNES, John M. (1970). Teoria Geral do Emprego, do Juro e do Dinheiro. Brasil/Portugal: Fundo de Cultura.

LAZZARATO, Michel (1997). Trabalho Imaterial. Rio de Janeiro: DP\&A.

MARX, Karl (1988). O Capital: Crítica da Economia Política. São Paulo: Nova Cultural.

MARX, Karl (1983a). O 13 de junho de 1849 (As lutas de classes na França de 1848 a 1850). In F. Fernandes (org.), K. Marx, F. Engels: História. São Paulo: Ática, pp. 252-279.

MARX, Karl (org.) (1983b ). O coup de main de Luís Bonaparte (O 18 Brumário de Luís Bonaparte). In F. Fernandes (org.), K. Marx, F. Engels: História. São Paulo: Ática, pp. 280-292.

ORGANIZAÇÃO DAS NAÇÕES UNIDAS PARA A EDUCAÇÃO, A CIÊNCIA E A CULTURA (1990). Declaração Mundial sobre Educação para todos: Satisfação das Necessidades Básicas de Aprendizagem. Jomtien: Unesco.

PEREIRA, Luiz Carlos Bresser (1996). Crise Econômica e Reforma do Estado no Brasil: para uma Nova Interpretação da América Latina. São Paulo: Editora 34.

PINTO, José Marcelino de Resende (2005). Os números do financiamento da educação no Brasil. Revista Pro-posições, Campinas, v. 85, n. 95.

POCHMANN, Márcio (2008). Riqueza concentrada e trabalho em excesso. Folha de $S$. Paulo, São Paulo: 3, 21 mar. 2008.

SGUISSARDI, Valdemar \& SILVA JÚNIOR, João dos Reis (2007). Segundo Relatório da Pesquisa Mercantilização da Esfera Pública e Universidade: nova Identidade Universitária e Trabalho Docente das Ifes Região Sudeste. Financiamento da Fapesp e do CNPq. São Carlos.

SGUISSARDI, Valdemar; SILVA JÚNIOR, João dos Reis \& HAYASHI, Carlos Roberto Massao (2006). Educação superior brasileira - São Paulo - 1991/4. In D. Ristoff \& J. Giollo (Org.), Educação Superior Brasileira 1991-2004. Inep: Brasília.

SILVA JÚNIOR, João dos Reis \& SGUISSARDI, Valdemar (1993). As Novas Faces da Educação Superior no Brasil: Reforma do Estado e Mudança na Produção. São Paulo: Cortez.

SMITH, Adam (1993). A Riqueza das Nações. v. 2. Lisboa: Calouste Gulbenkian. 
THE PROFESSOR AND RESEARCHER IN BRAZILIAN PUBLIC UNIVERSITY IN THE CONTEXT OF THE INTERNATIONALIZATION OF CAPITAL: THE PRODUTIVITY OF THE HIGHLY QUALIFIED IMMATERIAL LABOR

\section{Abstract}

The article's purpose is to understand the mercantilist process of the Brazilian public university and its institutional identity. We aim at understanding this event as a process of social streamlining, with origin at the reformed state and as a part of the legacy of the twentieth century with links to the internationalization of capitalism, which ended as a target of the naturalization of the public fund by capital, and resulting in the reforms of the Brazilien republican intitutions. The university, not without opposition from social, political and trade union movements and from intellectuals who still resist, is being transformed into an institution ruled by the capital and the state, with the market as a mediator. The market rationality has become the core of the policy (which should be the public administration directed for human being), with perverse consequences for the popular democratic government, which is distant from its origin, for the more critic intellectual thinking, to the left parties, for research on higher education public policy, but, over all, for the object that matters here: the activities and training of the teacher and the researcher of the public state universities in general. In addition, it is intended to show that the process of rationalization in its current historical form has as also historical essence the rationality of the social capitalism formation and it indirectly shows the course of this event.

Keywords

Higher Education Reform; Teaching formation; Alienation in the Teaching Work; Ontology in the Teaching Work 


\section{L'ENSEIGNANT — CHERCHEUR À L'UNIVERSITÉ PUBLIC DANS LE CONTEXE DE L'INTERNATIONALIZATION DU CAPITAL: LA PRODUCTIVITÉ DU TRAVAIL IMMATÉRIEL SURCALIFIÉ}

\section{Résumé}

L'objetif de ce texte consiste à comprendre le processus de marchandisation de l'université publique brésilienne et de son identité institutionnelle. II essaye de comprendre ce fait comme un processus de rationalisation sociale, originaire de l'État reformé et héritage de l'État-providence ariculé avec l'internationalisation du capitalism, processus qui a fait de l'université publique cible de la naturalisation du fond publique par le capital, comme l'on été diverses d'importantes réformes des institutions républicaines au Brésil. L'université, non pas sans l'opposition de certains mouvements sociaux, politiques et syndicaux, aussi que d'intellectuels qui encore resistent, est en train d'être summise à la tutelle du capital et de l'État, en ayant le marché comme opportun médiateur. La rationalité du marché s'est rendue le noyau de la politique (à la place de l'administration publique tournée vers l'être humain), avec des consequences perverses pour le gouvernement populaire démocratique - qui s'éloigne de son origine -, pour la pensée intellectuelle plus critique, pour la gauche partisane, pour la recherche sur les politiques publiques d'éducation supérieure, mais, surtout, pour l'objet qui ici intéresse examiner: les activités et la formation de l'enseignant/chercheur des universités publiques en general. En outre, il cherche à montrer que le processus de rationalisation, dans sa forme historique actuelle, a, comme essence, aussi historique, la rationalité de la formation sociale du capitalisme, et, par cette raison, explicite, indirectement, les orientations de cet évent.

Mots-clé

Éducation Supérieure; Formation enseignant; Alienation au travail enseignant; Ontologie dans le travail enseignant 